\title{
Polyfunctional Modifiers for Bitumen and Bituminous Materials with High Performance
}

\author{
Alim Feizrakhmanovich Kemalov (D), Ruslan Alimovich Kemalov, \\ Ilmira Maratovna Abdrafikova (D), Pavel Sagitovich Fakhretdinov, \\ and Dinar Zinnurovich Valiev \\ Department of High-Viscosity Oil and Natural Bitumen, Kazan (Volga Region) Federal University, 18 Kremlyovskaya Street, \\ Kazan 420008, Russia \\ Correspondence should be addressed to Alim Feizrakhmanovich Kemalov; alim.kemalov@mail.ru
}

Received 8 March 2017; Revised 15 July 2017; Accepted 24 August 2017; Published 3 January 2018

Academic Editor: Hainian Wang

Copyright (C) 2018 Alim Feizrakhmanovich Kemalov et al. This is an open access article distributed under the Creative Commons Attribution License, which permits unrestricted use, distribution, and reproduction in any medium, provided the original work is properly cited.

\begin{abstract}
Over the last decade increase in capacity and the intensity of vehicular traffic has increased manifoldly, including heavy trucks, super singles, and higher tire pressures, resulting in significant increase of dynamic loads on the road surface which in turn lead to high quality requirements for bitumen in order to avoid premature wear and failure of asphalt concrete pavements. One of the possibilities to increase the quality of bitumen is to use special additives and modifiers that can provide a high adhesion to mineral filler and inhibit the aging and degradation processes in the asphalt coating. To achieve this, in the present study composite modifiers based on bisimidazolines derivatives were synthesized. The developed polyfunctional modifier (PFM) of complex action provides enhanced thermal stability, significantly improves the adhesion between bitumen binder and aggregates, and also improves the physical-mechanical properties of the asphalt concrete. Based on the test results it is recommended to use the synthesized samples of the PFM additive with complex action in asphalt mixtures for road paving.
\end{abstract}

\section{Introduction}

Asphalt concrete (AC) coatings include two main components: bitumen and aggregates (crushed stone). Bitumen performs the function of a substance that binds particles of mineral material to form an asphalt concrete coating. Being nonpolar, bitumen has high waterproofing properties. It is known that high-resinous and low-paraffinic petroleum is the most suitable for the production of road and construction bitumen. However, due to the limited supply of this type of petroleum almost any oil residues are used. As a result, the quality of bitumen is very unsure at the moment and that leads to poor quality of bituminous materials resulting in poor quality asphalt concrete pavements.

At the same time, most of the used aggregates have a greater affinity for water than they do for bitumen binder [13]. Polycyclic aromatic compounds, resins, and heteroatomic compounds contained in the bitumen do not provide desired adhesion to the mineral part of asphalt concrete. Oxygenated compounds formed during the oxidation of vacuum residues also have little impact on the adhesive properties of bitumen [4-7].

Poor adhesion between the bitumen binder (BB) and aggregate may lead to stripping (delamination of the binder from the aggregate surface) in the presence of water which leads to pavement failure such as raveling, potholes formation, and rutting $[2,3,6-8]$. The situation is aggravated by the continuous increase in capacity and traffic volumes, including heavy truck axle loads, super singles, and high tire pressure that leads to a significant increase of dynamic loads on the pavement. Therefore, to obtain high quality pavements, key factor is in ensuring high adhesion between bitumen and the mineral component of pavement. For this reason adhesion additives are used; most frequently these are cationic surfactants [3, 7-11]. Classical cationic surfactants are diphilic structures in which nonpolar part is a long chain hydrophobic alkyl and the polar part (so-called "head") is a positively charged ammonium center, or nitrogen atom 
capable of being protonated in acidic mediums. This fundamental property, diphilicity, is the reason why surfactants are lined up at the interface "bitumen-mineral material" [59]. Herewith, the positively charged (hydrophilic) groups are fixed on polar surface of the mineral material and the hydrophobic hydrocarbon chains are fixed in the bitumen. Thus, the adhesive additive acts as bridge between bitumen binder and aggregates that is schematically presented in Figure 1.

Nowadays imidazolines and their derivatives (Іа-Ід) as well as bisimidazolines (IIa, IІб) $[9,11,12]$ that exhibit the ability to increase the bitumen adhesion to mineral material are most widely used as additives for bitumen; the mechanism of their action is shown schematically on Figure 2. Adhesion additive "Amidan" [12], which presents the technical product, containing a mixture of imidazoline (Іа-Ід) and bisimidazoline (ІІа, ІІб) derivatives, can be taken as example.<smiles>[R]C1=NCCN1[X]</smiles>

(I)<smiles>[R]C1=NCCN1CCN1CCN=C1[R]</smiles>

(IIa)<smiles>[R]C1=NCCN1CCNCCN1CCN=C1[R]</smiles>

where $\mathrm{R}=$ alkyl or alkenyl (in all the structures (I-II)); X are the possible substituents in (I) with the following structures (Іа-д):

$$
\begin{aligned}
& \mathrm{X}=\mathrm{H} \text { (Iа), } \\
& \mathrm{X}=\mathrm{CH}_{2}-\mathrm{CH}_{2}-\mathrm{NH}_{2} \text { (Іб), } \\
& \mathrm{X}=\mathrm{CH}_{2}-\mathrm{CH}_{2}-\mathrm{NH}-\mathrm{C}-\mathrm{R} \text { (Ів), } \\
& \mathrm{X}=\mathrm{CH}_{2}-\mathrm{CH}_{2}-\mathrm{NH}-\mathrm{CH}_{2}-\mathrm{CH}_{2}-\mathrm{NH}_{2} \text { (Іг), } \\
& \mathrm{X}=\mathrm{CH}_{2}-\mathrm{CH}_{2}-\mathrm{NH}-\mathrm{CH}_{2}-\mathrm{CH}_{2}-\mathrm{NH}-\mathrm{C}-\mathrm{R} \text { (Ід) }
\end{aligned}
$$

Composite modifiers such as sulfur, rubber (polybutadiene, natural rubber, butyl rubber, chloroprene, etc.), organic-manganese compounds, thermoplastic polymers (polyethylene, polypropylene, polystyrene, ethylene-vinyl acetate (EVA)), thermoplastic rubbers (polyurethane, olefin copolymers, and block copolymers of styrene-butadienestyrene (SBS)) are also used in order to improve physicalchemical properties of $\mathrm{BB}$ as well as the physical-mechanical properties of AC [13-15].

The effectiveness and quality of additives are largely related to their thermal stability, and this is due to the following reasons (most relevant for Russia):
(1) Road bitumen is produced in bulk by liquid-phase oxidation of vacuum residue, the optimal process temperature is $250^{\circ} \mathrm{C}$, and it is more viable to inject the additive to the oxidized bitumen directly at its outlet from the oxidation column, to obtain bitumen with improved adhesion properties.

(2) The hot-mix asphalt concrete is the most used in road construction, and the compounding of bitumen with mineral material is carried out at relatively high temperatures (160-170 $\left.{ }^{\circ} \mathrm{C}\right)$.

It should be emphasized that a disadvantage of modern adhesive modifiers for bitumen is that they demonstrate a low thermal resistance (up to $120-175^{\circ} \mathrm{C}$ ), while for some systems there is a rapid loss of adhesion at $150^{\circ} \mathrm{C}$. On the other hand their use often leads to deterioration of physical-mechanical properties of the corresponding AC [16].

Thus, the aim was to develop the new modifiers with increased thermal stability (up to $220-240^{\circ} \mathrm{C}$ ) that would be capable of increasing the adhesion between bitumen and aggregates and improving elasticity of the binder, that is, the polyfunctional modifiers (PFM).

\section{Materials and Methods}

According to the concept of nonclassic cationic surfactants $[17,18]$, they have hydrophobic hydrocarbon chains which are fragmented (broken) by polar heteroatomic groups. This structure ensures their physical and chemical properties and adsorption behavior, different from the classic surfactants. Based on this concept high-performance chemicals were obtained that were useful for the production, treatment, and transportation of petroleum as well as for the production of corrosion inhibitors, emulsifiers, demulsifiers, the biologically active substances, and so on [17-19]. We used the same concept to develop desired nitrogen-containing compounds.

2.1. Modifiers Synthesis. In accordance with the concept of nonclassical surfactants, we had assumed that it is necessary to increase polarity of the molecule of constructed imidazolines by increasing the number of polar imidazoline centers from one to two in order to create compounds with needed properties, as well as to introduce nonclassical spacer into the molecule, wherein the hydrophobicity of an alkyl chain is broken (fragmented) by one or more alkanoylamide fragments:

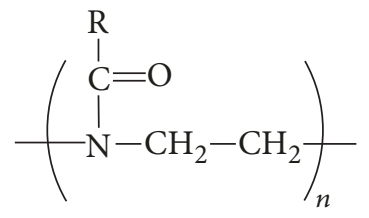

On one hand, this structure of the spacer provides an increase in the molecule polarity that is responsible for interaction between bitumen and hydrophilic surface of the aggregates, because extra polar amide groups appear along with two imidazoline cycles. On the 


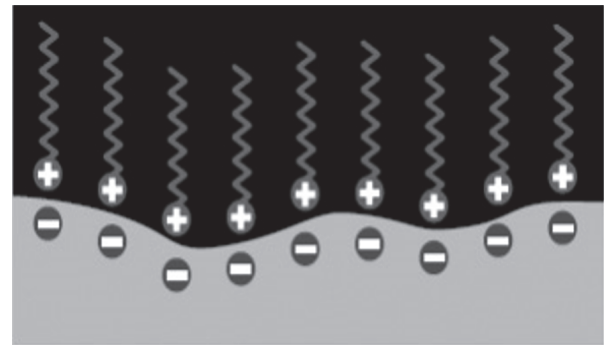

FIgURE 1: Cationic surfactants as a bridge between the bitumen and aggregates.

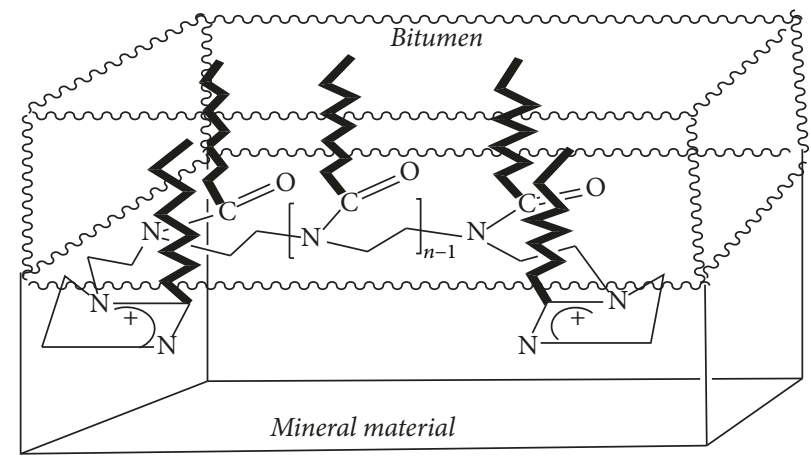

FIGURE 2: Location of bisimidazoline molecules on the interface "bitumen-mineral material."

other hand, the use of alkanoylamide fragments allows introducing additional hydrophobic long chain alkyl groups which increase the possibility of adhesive to fix in the bitumen media. This enhances the adhesive properties of the designed compounds. As a result, we obtained $\mathrm{N}$-acylated bisimidazolines with (ethylene-Nalkanoylamide) spacers, namely, $1-\left(2^{1}\right.$-alkylimidazolinyl- $\left.1^{1}\right)$ 2-[( $2^{2}$-alkylimidazolinyl-1 $\left.{ }^{2}\right)$-poly(ethylene-N-alkanoylamide)]ethanes, containing two imidazoline cycles, connected by spacers:<smiles>[R]C(=O)N(CCC(C)(C)CCN1CCN=C1[R])C(C)(C)CCN1CCN=C1[R]</smiles>

(IIIa-IIIв)

where $\mathrm{R}=\mathrm{CH}_{3}-\left(\mathrm{CH}_{2}\right)_{7}-\mathrm{CH}=\mathrm{CH}-\left(\mathrm{CH}_{2}\right)_{7}-; n=1$ (IIIa), $n=$ 2 (ІІІб), and $n=3$ (ІІІв).

The authors assumed that this construction of the additive would lead to increasing of bitumen adhesion to the mineral component of pavement. Furthermore, the conversion of the secondary amino groups into alkanoylamides should also increase significantly the thermal stability of designed compounds due to the fact that tertiary amides are more stable than the starting amine-compounds.

The desired spacers were obtained with the average yield (the ratio of the mass of the obtained product to the mass of the starting material) of up to $90 \%$, and are viscous and pasty brown liquids, the physicochemical characteristics of which are given in Table 1.
The starting amino-compound and the resulting compounds were analyzed by the conventional method of potentiometric titration of a mixture of primary, secondary, and tertiary amines with the definition of the total basicity $B_{\mathrm{T}}$, the basicity of secondary and tertiary amines $B_{2,3}$, and the basicity of tertiary amines $B_{3}$. Then the joint basicity of tertiary amines and amides $\mathrm{B}_{3+\text { amide }}$ was determined by potentiometric titration of the sample weight of test substance in acetic anhydride (as solvent) with the use of $0.1 \mathrm{~N}$ solution of $\mathrm{HClO}_{4}$ in glacial acetic acid. The basicity of amides $\mathrm{B}_{\text {amide }}$ was determined by the difference between the basicity $\mathrm{B}_{3+\text { amide }}$ and the basicity $\mathrm{B}_{3}$ [20]. The results of obtained compounds analysis are shown in Table 1.

The FTIR spectra of the additives and the original bitumen are presented in Figure 3. 
TABLE 1: Physicochemical characteristics of $\mathrm{N}$-acylated bisimidazolines derivatives (IIIa-IIIв).

\begin{tabular}{|c|c|c|c|}
\hline Compound & $\begin{array}{l}\begin{array}{l}\text { Elemer } \\
\text { found/ }\end{array} \\
\mathrm{C}, \%\end{array}$ & $\mathrm{~N}, \%$ & $\begin{array}{l}\text { Basicity of amides, } \\
\mathrm{ml} 0.1 \mathrm{~N} \mathrm{HClO}_{4} / \mathrm{g} \\
\text { found/calculated }\end{array}$ \\
\hline (IIIa) & $78.57 / 78.64$ & $7.29 / 7.40$ & $10.49 / 10.56$ \\
\hline (ІІІб) & $78.41 / 78.51$ & $6.63 / 6.70$ & $15.85 / 15.94$ \\
\hline (IIIв) & $78.32 / 78.43$ & $6.19 / 6.28$ & $19.18 / 19.21$ \\
\hline
\end{tabular}

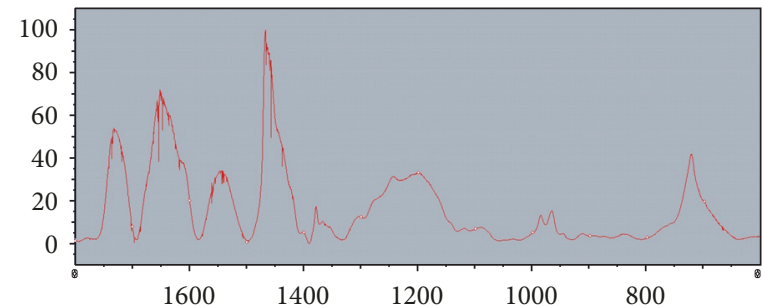

(a)

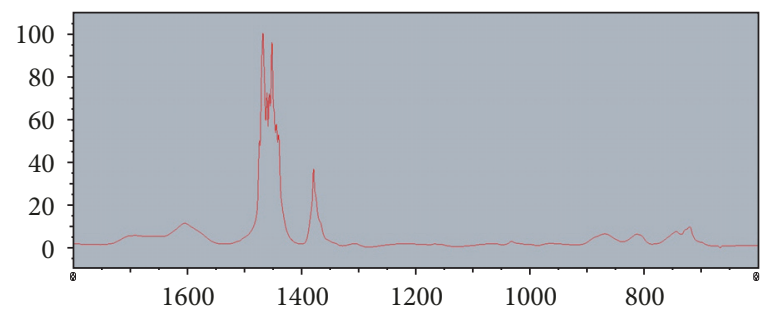

(b)

FIGURE 3: IR spectra of the additives (a) and the original bitumen BND 60/90 (TAIF-NK) (b).

Absorption bands with the following wave numbers were observed in the IR spectra of the obtained compounds (Figure $3(\mathrm{a})): v \mathrm{C}=\mathrm{N}=1600-1630 \mathrm{~cm}^{-1}$, indicating the presence of imidazoline cycles; $v \mathrm{C}=\mathrm{O}=1740-1745 \mathrm{~cm}^{-1}, v-\mathrm{N}(\mathrm{CO}) \mathrm{R}$ $=1660 \mathrm{~cm}^{-1}$, and $v \mathrm{CN}=1260-1300 \mathrm{~cm}^{-1}$ can be related to alkanoylamide structures; $\delta\left(\mathrm{CH}_{2}\right)_{x}=720 \mathrm{~cm}^{-1}$ - corresponds to pendular oscillation of alkylene structure in a chain [21]. Wide absorption bands at $1600 \mathrm{~cm}^{-1}$ in FTIR spectra of the original bitumen (Figure 3(b)) stand for the $v \mathrm{CH}$ bond in aromatic ring; sharp absorption bands with high intensity at 1440 and $1460 \mathrm{~cm}^{-1}$ correspond to stretch vibration of $-\mathrm{CH}_{2}-$ structure fragment in long chains, confirming high content of paraffin waxes; absorption band at $1375 \mathrm{~cm}^{-1}$ is related to methyl groups.

\subsection{Bitumen Modification and Performance Properties Analy-} sis. Investigation of the effect of the synthesized compounds on the adhesion between bitumen and the mineral material was carried out by the use of example of oxidized bitumen of 60/90 penetration grade (BND 60/90 (the mark of bitumen in Russia means "petroleum bitumen for roads")) that was produced in TAIF-NK PSC, with the following group chemical composition, wt.\%: 22.62 of saturates (including $10.2 \%$ of paraffin waxes), 15.14 of aromatics; 40.26 of resins; 21.98 of asphaltenes. follows:

The bitumen modification process was carried out as

(1) The BND was heated in a metal vessel to the temperature of $80^{\circ} \mathrm{C}$ with the use of stirring mechanism, kept under thermostatic control for 20 min to obtain homogeneous diluted substance with homogeneous distribution of components;
(2) The BND was gradually heated to the temperature of $120-130^{\circ} \mathrm{C}$, at which it was kept for $20 \mathrm{~min}$;

(3) Obtained PFM substances were injected into the heated bitumen and stirred for 20-30 min to ensure homogenous dispersion of the PFM in bitumen media.

The adhesion between bitumen and aggregates (mineral material) testing was conducted in accordance with GOST (GOST, Russian state standard) 12801-98 [22], the essence of which is to determine the ability of the viscous bitumen that is precoated on the surface of mineral material to persist on it while being exposed by water. The quality of the adhesion assessment was rated according to Table 2 .

The ability of bitumen to coat aggregates was evaluated based on contact angle measurement. Original BND 60/90 and modified by PFM in amount of $0.6,0.8,1.0$, and $1.2 \mathrm{wt} . \%$ were taken. The contact angle of wetting was determined on two surfaces: on glass which is the standard of the polar surface, as well as mineral rocks of various genesis: (dolomitized limestone, consisting of 90\% dolomite and 10\% calcite) from "Bianca gravel factory," chemical compositions of which are presented in Tables 3-4. Pervouralsk aggregates were considered to be of "acidic" nature; Bianca - is of "basic" nature.

Measurements were carried out using cathetometer KM8 by direct measurement of the base and height of the drop with subsequent calculation [23]. The cosine of the contact angle of the drop is calculated by the formula

$$
\cos \theta=\frac{r^{2}-h^{2}}{r^{2}+h^{2}}
$$

where $r=L / 2$ is the droplet radius, $L$ is the droplet base, and $h$ is the droplet height. With the help of a cathetometer, the contact angles of the taken aggregates wetting by bitumen 
TABLE 2: Evaluation of grip (adhesion).

Feature of the bitumen film on the surface of crushed stone

Evaluation of grip

Binder film is completely retained on the surface, local decreasing of the thickness of a film can be observed

Excellent (five points)

Binder film is completely retained on the surface but is partially separated from the sharp corners and edges

Good (four points)

Binder film is retained on over $50 \%$ of crushed stone surface

Satisfactory (three points)

Binder film is retained on less than $50 \%$ of crushed stone surface. On the exposed surface individual bitumen

droplets are observed

Poor (two points)

TABLE 3: Chemical composition of the "Pervouralsk mine management" gravel.

\begin{tabular}{cccccccccccccc}
\hline \multicolumn{10}{c}{ Content in terms of dry matter, wt.\% } \\
$\mathrm{SiO}_{2}$ & $\mathrm{TiO}_{2}$ & $\mathrm{Al}_{2} \mathrm{O}_{3}$ & $\mathrm{Fe}_{2} \mathrm{O}_{3}$ & $\mathrm{FeO}$ & $\mathrm{CaO}$ & $\mathrm{MgO}$ & $\mathrm{MnO}$ & $\mathrm{K}_{2} \mathrm{O}$ & $\mathrm{Na}_{2} \mathrm{O}$ & $\mathrm{V}_{2} \mathrm{O}_{5}$ & $\mathrm{P}_{2} \mathrm{O}_{5}$ & $\mathrm{~S}$ \\
\hline 22,1 & 3,27 & 11,7 & 27,2 & 16,9 & 8,9 & 9,0 & 0,23 & 0,2 & 0,14 & 0,4 & 0,01 & 0,03 \\
\hline
\end{tabular}

TABLE 4: Chemical composition of the "Bianca gravel factory" gravel.

\begin{tabular}{lccccccc}
\hline & \multicolumn{9}{c}{ Content in terms of dry matter, wt.\% } \\
$\mathrm{SiO}_{2}$ & $\mathrm{Fe}_{2} \mathrm{O}_{3}$ & $\mathrm{CaO}$ & $\mathrm{MgO}$ & $\mathrm{Al}_{2} \mathrm{O}_{3}$ & $\mathrm{SO}_{3 \text { общ }}$ & $\mathrm{CaCO}_{3}$ & $\mathrm{MgCO}_{3}$ \\
\hline 3,3 & 0,7 & 20,9 & 11,9 & 0,8 & 0,3 & 37,2 & 24,9 \\
\hline
\end{tabular}

binder samples were determined. The drop of bitumen (of the same size and mass, as far as possible) was laid onto the surface of a substrate, at a bitumen temperature of $130^{\circ} \mathrm{C}$. As the drop of bitumen cools instantly as soon as it reaches the cold substrate surface, the samples of the stone materials were heated to $40^{\circ} \mathrm{C}$, which practically did not change the surface properties of the rock, but retained the liquid state of the bitumen for a sufficient time. The equilibrium value of the wetting contact angle was determined on the basis of the kinetic curves. The wetting angle was measured twice: immediately after the dropping of the bitumen and after 1 minute, necessary to achieve equilibrium wetting angle. The latest value was taken into account.

It is known that adhesion of bitumen to mineral materials is the work required to separate the bitumen layer from these materials. In order to determine the work of adhesion (a quantitative measure) between aggregates and bitumen, we measured the surface tension of bitumen in the presence of the PFM. Surface tension at the interface between binder and air phases $\left(\sigma_{\mathrm{BA}}\right)$ is the most important factor determining the intensity of wetting of a mineral substrate by bitumen. Surface tension measurements were carried out at a temperature of $25^{\circ} \mathrm{C}$ using EasyDyne S K20S tensiometer (KRUSS) by the Du Nui ring method. Bitumen samples were dissolved in toluene at a mass ratio of toluene : bitumen equal to $1: 1.5$.

Based on the obtained values of $\theta$ and $\sigma$, the wetting energy or the adhesive stress was calculated.

$$
W_{e}=\sigma \times \cos \theta .
$$

The work of adhesion was calculated using Young-Dupré equation:

$$
W_{a}=\sigma \times(1+\cos \theta) .
$$

The work of cohesion was calculated to assess the interaction strength between the bitumen components. The work of cohesion is determined by the expenditure of energy on the reversible rupture of the body over a section equal to unit of area. Since, as a result of a rupture, a surface with two-unit area forms, the work of cohesion is as follows:

$$
W_{k}=2 \sigma .
$$

To characterize the wetting process, the spreading coefficient $S$ is used which is taken as the difference between the work of adhesion $W_{a}$ and the work of cohesion $W_{k}$. For the complete wetting $S \rightarrow 0$.

$$
S=W_{a}-W_{k}=\sigma_{l} \times(\cos \theta-1) .
$$

The relationship between the work of adhesion and cohesion can be expressed through a relative value, a relative adhesion work of liquid, $Z_{a}$ :

$$
Z_{a}=\frac{W_{a}}{W_{k}}
$$

If $W_{a}$ and $W_{k}$ are expressed in terms of the quantities defined in (3) and (4), then

$$
Z_{a}=\frac{1+\cos \theta}{2} .
$$

To study the dynamic viscosity (according to ASTM D4402) of modified bitumen samples, dynamic tests were carried out using Rheotest RN 4.1. We obtained the dependence of dynamic viscosity (mPa.s) from temperature $\left({ }^{\circ} \mathrm{C}\right)$ at a constant shear rate $\left(100 \mathrm{~s}^{-1}\right)$. The measurements were carried out in the following way: first, the measuring system "cone-plate" was heated to $125^{\circ} \mathrm{C}$, on which bitumen samples were laid (original bitumen and the bitumen modified by 0.6 , $0.8,1.0$, and $1.2 \mathrm{wt} . \%$ of PFM, resp.); then the measurements were taken along with cooling of the samples. In order to study the thixotropic properties of the samples, immediately 
TABle 5: Physical-chemical characteristics of the PFM.

\begin{tabular}{lccc}
\hline Number & The name of indicators & The meaning & Testing method \\
\hline$(1)$ & Appearance & The viscous honey-like mass & Visually \\
$(2)$ & Colour & From light yellow to dark brown & Visually \\
$(3)$ & Smell & Weak, characteristic & Organoleptic \\
$(4)$ & Density at $20^{\circ} \mathrm{C}, \mathrm{g} / \mathrm{cm}^{3}$ & 0.9538 & GOST $3900-85$ \\
$(5)$ & Kinematic viscosity at $100^{\circ} \mathrm{C} \mathrm{mm}^{2} / \mathrm{s}$ & 139.6 & GOST 33-2000 \\
\hline
\end{tabular}

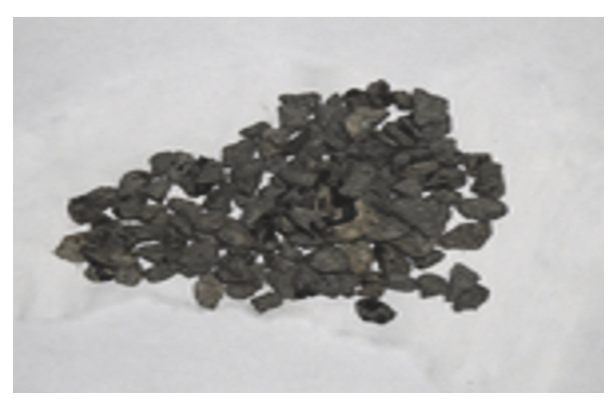

(a)

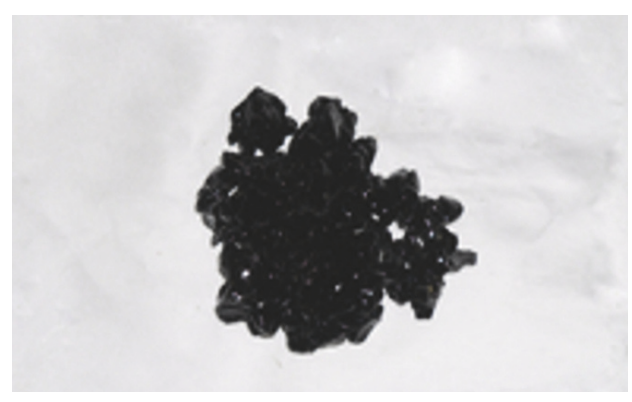

(b)

FIGURE 4: The results of the impact of adhesion additive on the adhesion between bitumen and aggregates: (a) the original bitumen $60 / 90$ without additive; (b) bitumen with 1 wt.\% of PFM.

after direct measurements, the viscosity was measured in the opposite direction, with a decrease in the shear rate from 1000 to $1 \mathrm{~s}^{-1}$ at temperatures of $80-120^{\circ} \mathrm{C}$.

The properties of binders such as softening temperature (EN 1427, ASTM D36, AASHTO T53), brittleness temperature according to Fraas (i.e., the Fraass Breaking Point, EN 125932013), penetration (EN 1426, ASTM D5, AASHTO T49), ductility (EN 13398/13587/13589, ASTM D 113, AASHTO T 51), and the change of the bitumen softening temperature after heating were determined according to GOST 2224590 "Viscous petroleum road bitumen" [24]. First, bitumen samples are heated in the drying oven at a temperature of $163^{\circ} \mathrm{C}$ for 5 hours in accordance with GOST 18180-72 [25], after which the softening temperature is determined. Density at $20^{\circ} \mathrm{C}$ and kinematic viscosity at $100^{\circ} \mathrm{C}$ were determined in accordance with GOST 3900-85 [26] and GOST 33-2000 [27], respectively.

The thermal stability test of modified bitumen was carried out at temperatures of 163,180 , and $200^{\circ} \mathrm{C}$ and a heating duration of 25 hours ( $\max$ ) with the use of stone materials of basic and acidic nature. The temperature of $163^{\circ} \mathrm{C}$ is specified by GOST 18180-72 [25] and ASTM D 2872 [28]. The temperatures of 180 and $200^{\circ} \mathrm{C}$ were chosen upon the recommendations of road constructing organizations. The modified bitumen, that was under a thermal exposure, was sampled every 5 hours, and then the adhesion test was conducted according to the above-mentioned technique. Bitumen binder can be stored at bitumen storage, where it is constantly heated to keep fluidness, for maximum $24 \mathrm{~h}$ before it is directed to an asphalt concrete mixing vessel. For that reason the maximum duration of heating $(25 \mathrm{~h})$ was chosen that exceeds possible storage period.
Pilot-scale tests were also conducted as well as the technical inspection of asphalt concrete mixtures; the results of the latest were compared with the GOST 9128-2009 [29] requirements.

\section{Results and Discussion}

3.1. Comparative Study of the Obtained Additives and Their Effect on Bitumen Properties. The features and advantages of the PFM compared to adhesive "Amidan" are the following: high adhesion (at high temperatures as well), thermal stability at $250-270^{\circ} \mathrm{C}$ within 4 hours (compared to the values of $120-175^{\circ} \mathrm{C}$ ), high flash point, and high processability, the possibility of dosing directly into the bitumen that is outflow of the oxidizing column with a temperature up to $280^{\circ} \mathrm{C}$. PFM includes both polymer and adhesive characteristics, which affects the production costs. Despite the fact that additive is doped in small amounts (up to $0.8-1.0 \mathrm{wt}$.\%), they also affect the physical-chemical properties of the final AC. The specially designed spacer's structure enables starting of secondary polymerization processes taking place between asphaltenic and resinous compounds in bitumen media.

Physical-chemical characteristics of the synthesized PFM are presented in Table 5.

Research of the polyfunctional modifier influence on the adhesion between bitumen and the aggregates (mineral material) was carried on the above-mentioned sample of $60 / 90$ bitumen of OAO TAIF-NK production, with the characteristics shown in Table 6. As it can be seen from the data in Table 6, proposed compounds added at amounts of $0.5-1.0 \%$ have improved adhesion between bitumen and the mineral filler surface, corresponding to five points in accordance with GOST 12801-98.

Pictures taken after the performed adhesion test are presented on Figure 4. When a mineral material is coated 


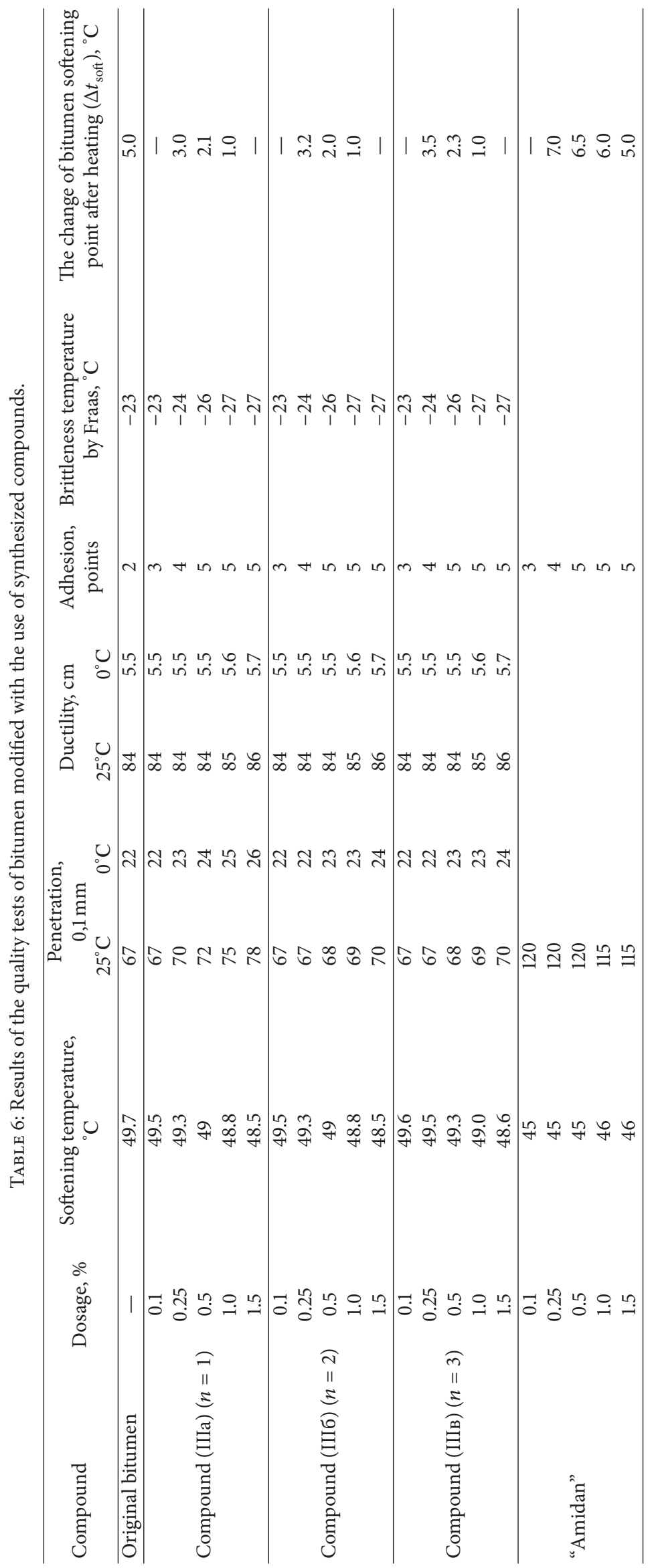


TABLE 7: Surface tension of the bitumen samples.

\begin{tabular}{lcccc}
\hline \multirow{2}{*}{ Bitumen samples } & \multirow{2}{*}{ Original } & \multicolumn{3}{c}{ PFM content, wt.\% } \\
& & 0.6 & 0.8 & 1.0 \\
\hline Average value, $\sigma_{l}, \mathrm{mN} / \mathrm{m}$ & 33.04 & 31.38 & 31.34 & 31.46 \\
\hline
\end{tabular}

with the original bitumen (i.e., without modifying additives), the binder film is persistent on the area of less than $50 \%$ of stones' surface, corresponding to 2 points. Addition of $1 \mathrm{wt} . \%$ of modifier leads to complete coverage of the mineral material surface, corresponding to 5 points.

The use of PFM improves the thermal stability of bitumen (Table 6). Thus, bitumen with PFM additive amounts of $0.9-1.0$ wt. $\%$ has low $\Delta t_{\text {soft }}$, equal to $1^{\circ} \mathrm{C}$, while for the bitumen with "Amidan" $\Delta t_{\text {soft }}$ equals $6^{\circ} \mathrm{C}$. In addition, there has been improvement in the penetration, which indicates the bitumen binder improved plasticity.

The test results indicate the fact that the increase in the content of adhesive additives in the range from 0 to $1.5 \mathrm{wt} . \%$ leads to increase of penetration values (at $25^{\circ} \mathrm{C}$ ), namely, from 67 to $78(0.1 \mathrm{~mm})$, respectively (Table 6).

The results of adhesive additive "Amidan" testing (Table 6) indicate deterioration of the bitumen properties. Though the adhesion is equal for both adhesives, "Amidan" acts as a diluting agent, leading to increase in the penetration value. The latest would lead to fractionation (i.e., delamination) of the binder in the process of its application. The changes of "Amidan"-modified bitumen softening temperatures after heating are too high, do not meet the standard requirements, and mean low stability of the binder. For that reason no further tests were carried out for bitumen containing "Amidan."

Regarding the brittleness temperature, determined according to Fraas (the Fraass Breaking Point), it indicates the lower temperature at which the bitumen loses viscoplastic properties and, as a consequence, becomes brittle. It is known that the lower the brittle point, the wider the temperature range in which the bitumen is in the viscoplastic state and, therefore, the better its physical-mechanical characteristics. In this case, the additive doping allows reducing the brittle point and, consequently, providing expansion of ductility temperature range. Apart from the above-mentioned advantages, it should be noted that the compounds are superior to "Amidan" in adhesion at high temperatures. Thus, the modified bitumen with additives amount of 0.9-1.0 wt.\% shows high adhesion to sand (5 points) after thermal exposure at temperatures of $220-240^{\circ} \mathrm{C}$ for 12 hours. It should be noted that the bitumen with the same amounts "Amidan" exhibits much lower thermal stability, providing similar adhesion only at temperatures above $170^{\circ} \mathrm{C}$.

3.2. Contact Angle Measurements and Adhesion Work Calculation. Figure 5 shows the dependence of the glass surface wetting contact angle on the content of the additive. It is established that bitumen does not wet the glass because $\cos \theta$ has negative values. Doping the proposed additive into bitumen results in a slight increase in wetting ability, an extremum is observed with an additive content of $0.8 \%$.

Figure 6 shows the dependence of the aggregates wetting contact angle on the content of the additive. It can be seen that the presence of an additive significantly changes the wetting of the mineral substrate by the modified bitumen; a wetting inversion is observed; that is, $\cos \theta$ increases with increasing content of the additive and acquires positive values. We note that, in the case of the surface of mineral materials, an extremum is also observed with an additive content of $0.8 \%$ by weight.

Surface tension measurements results are presented in Table 7.

The data in Table 7 indicates that the surface tension decreases with the addition of the additive. This agrees with the data of [30] that the surface tension at the bitumen-solid interface decreases with increasing of surfactants content. Surface tension in combination with adhesion properties provides information of the strength of the bitumen adherence to mineral material.

The calculated values of the above-mentioned characteristics of the "aggregates-organic binder" system surface properties, that is, wetting energy, adhesion work, cohesion work, spreading coefficient, and relative adhesion work, are presented in Table 8.

The analysis of the obtained data shows that the PFM, being adsorbed at the interface, promotes better wetting of the aggregates surface with bitumen. In this case, the contact angle $\theta$ decreases, the spreading coefficient and relative adhesion work increase reaching a peak when an additive content is $0.8 \mathrm{wt} . \%$, and cohesion work is reduced.

The value of $Z_{a}$ approaches 1 . Consequently, the adhesion forces between bitumen and mineral materials approximate in magnitude to the binding forces of the bitumen molecules. This contributes to the formation of a material with a homogeneous defect-free structure.

\subsection{Component Composition and Dispersity of the Bitumen.} Information on the component composition can play an important role in studying the changes occurring as a result of bitumen modification (Table 9). Thus, when introducing the developed additive into the initial bitumen in an amount of about $1 \%$ by weight, mainly the content of saturates in the direction of decrease and asphaltenes in the direction of increase is changing. In this case, the relative and absolute changes of the remaining groups of components are insignificant.

The sequence of hydrocarbon group transitions in this case can be delineated as follows [31]: 


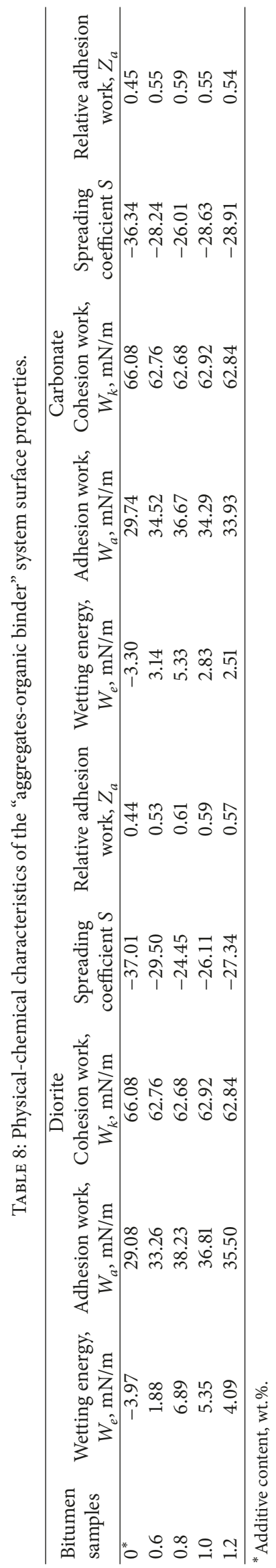




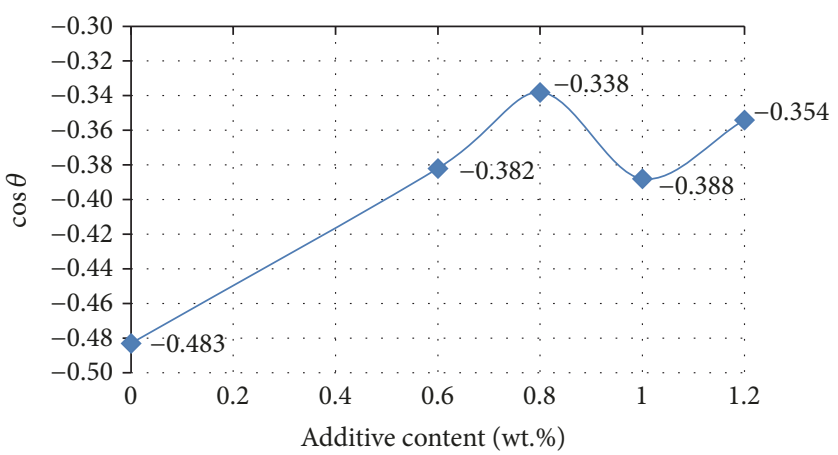

Figure 5: Dependence of the glass surface wetting contact angle on the content of the PFM.

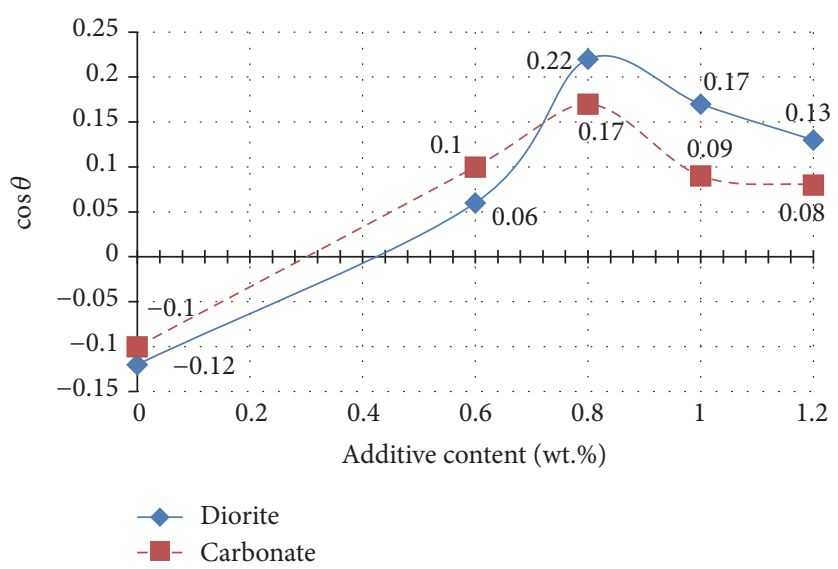

FIGURE 6: Dependence of the substrates surface wetting contact angle on the content of the PFM.

where PCA is polycyclic aromatics and MCA is monocyclic aromatics.

One of the most important characteristics of oil disperse system (ODS) is stability, since it affects the ability of the system to resist internal processes of interaction of particles with each other, which can lead to changes in the particle size of the dispersed phase and maintain an equilibrium distribution of dispersed phase particles in the medium [32]. Therefore, the radius of the particles of the dispersed phase can reach only certain limiting sizes, because the process of stratification can begin because of the difference in the densities of the phase and the medium. The sizes of dispersed particles can change under the influence of external factors (like temperature fluctuations, the action of shear deformations of the medium, the action of various additives, etc.) [32]. In this connection, it was necessary to examine the change in sizes of dispersed particles of bitumen affected by PFM doping. The results obtained are presented in Figure 7.

As can be seen from the results of measurements, in the medium of toluene-heptane mixture, regardless of the ratio of solvents, the smallest particle diameter corresponds to the additive in bitumen composition equal to $0.8 \%$ by weight. This is due to the fact that the additive provides the destruction of aggregate combinations with the formation of smaller structures together with their solvation. This may indicate that the bitumen system with this PFM content is in a state that can be conditionally called an "active state" (the core is minimal and the thickness of the solvate shell is maximal) [32]. Apparently, with a further increase in the dosage of the additive, a phase inversion, that is, enlargement of particles, takes place.

Thus, the PFM doping into bitumen and its heating at $120-130^{\circ} \mathrm{C}$ alters the behavior of some hydrocarbon groups in comparison with the behavior of these groups in the absence of an additive. Based on the results of the group chemical composition, it can be concluded that the additive is distributed mainly between monocyclic aromatic hydrocarbons and asphaltenes. As a result of the study of the particle size, it has been established that the system is in the most "active state" with an additive content of PFM in an amount of $0.8 \%$ by weight.

3.4. Rheological Properties of Modified Bitumen. The rheological properties of the ODS essentially depend on their composition and primarily on the content of the main 
TABLE 9: Group chemical composition of the original and modified bitumen.

\begin{tabular}{|c|c|c|c|c|c|}
\hline \multirow{3}{*}{$\begin{array}{l}\text { Components, } \\
\text { wt. } \%\end{array}$} & \multicolumn{5}{|c|}{ Bitumen samples } \\
\hline & \multirow{2}{*}{ Original } & \multicolumn{4}{|c|}{ PFM content, wt. $\%$} \\
\hline & & 0.6 & 0.8 & 1.0 & 1.2 \\
\hline Saturates (S) & 22.62 & 18.45 & 18.63 & 14.18 & 14.2 \\
\hline $\operatorname{Aromatics}(M C A)^{*}$ & 6.88 & 8.74 & 9.77 & 12.65 & 12.07 \\
\hline Aromatics $(B C A+P C A)^{*}$ & 8.26 & 7.98 & 7.66 & 6.85 & 7.92 \\
\hline Aromatics (A) & 15.14 & 16.72 & 17.43 & 19.5 & 19.99 \\
\hline Resins (R) & 40.26 & 39.47 & 39.07 & 40.65 & 39.92 \\
\hline Asphaltenes (A) & 21.98 & 25.36 & 24.87 & 25.67 & 25.89 \\
\hline
\end{tabular}

${ }^{*}$ MCA: monocyclic aromatics, BCA + PCA bicyclic and polycyclic aromatics.

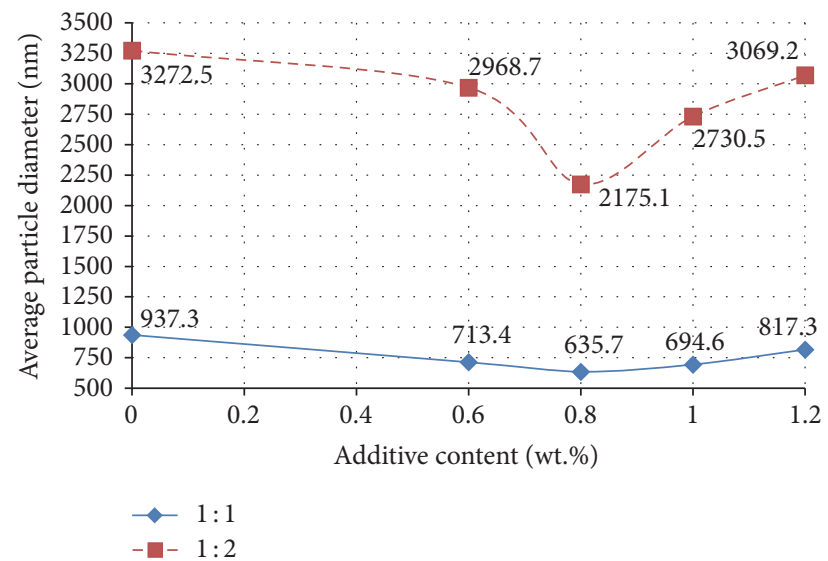

FIGURE 7: Dependence of the average diameter of dispersed particles from the content of the additive in toluene: heptane medium.

structure-forming components, which include the most high-molecular components, resinous-asphaltene substances (RASs), as well as paraffins at temperatures below their crystallization temperature, which can significantly influence on the properties of bitumen [31-33].

Viscosity increases in proportion to the volume of particles of the dispersed phase and the degree of their aggregation [31-33]. Aggregation of particles leads to an increase in apparent viscosity, since aggregates reduce the effective crosssection of the flow channel and create additional inhibition of the displacement of the fluid layers [33]. Destruction of the structure or deformation of solvate shells causes an anomaly of viscosity.

Effective regulators of viscosity and the ultimate shear stress of asphaltene-containing ODS are surfactants that exert peptizing action, blocking the adhesion planes of particles and decreasing the strength of contact between the layers of the dispersion medium through which the particles of the disperse phase contact [33].

The viscosity of bitumen depends not only on the composition of bitumen and its temperature, but also on the duration and nature of the action of the load. The graph of viscosity change with temperature is shown in Figure 8. As can be seen, when all the samples are cooled, the viscosity increases equally, but in the initial bitumen, the fracture, that

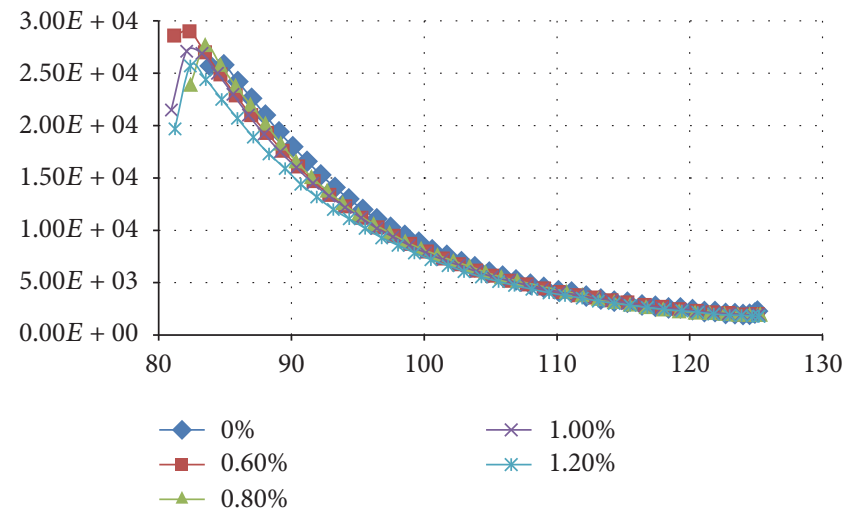

FIGURE 8: Dependence of viscosity on temperature.

is, destruction of the structure, begins at a higher temperature $\left(85^{\circ} \mathrm{C}\right)$ than in the modified ones. This temperature corresponds to the highest viscosity of the original unmodified bitumen and is equal to $2.58 \cdot 10^{4} \mathrm{mPa} \cdot \mathrm{s}$.

Figure 9 shows the thixotropy curves of bitumen samples at different temperatures in semilogarithmic coordinates. It should be noted that, at temperatures of $80-90^{\circ} \mathrm{C}$, viscosity increase is observed in samples of modified bitumen. The additive can promote formation of spatial structures due to the formation of complex structural unit (CSU), conjugated with the available particles of the dispersed phase [32]. In this case, the properties of the binder will be determined by this new spatial conjugate structure [32].

We assume that the additive provides destruction due to peptization of aggregate combinations of asphaltenes with the formation of highly disperse RASs; that is, asphaltenes disperse into smaller structures. This conforms to data on the average particle diameter (Section 3.3), in which the smallest particle diameter corresponds to the dosage of the additive in the bitumen of $0.8 \mathrm{wt} . \%$. As a result, the amount of particles increases and thereby the viscosity increases due to the larger contact surface. Summarizing the foregoing, we should note that the additive has a structuring effect on the properties of road bitumen that is expressed in the formation of a spatial dispersed structure, conjugated with asphaltene complexes of bitumen [31]. The structuring effect is manifested with a certain concentration and only in the presence of a spatial 


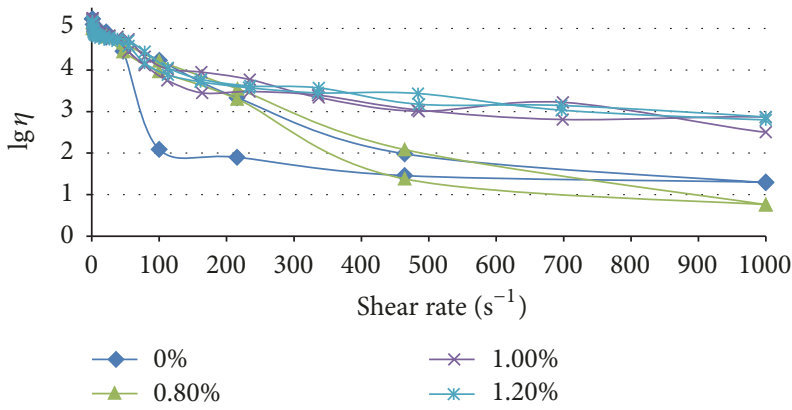

(a)

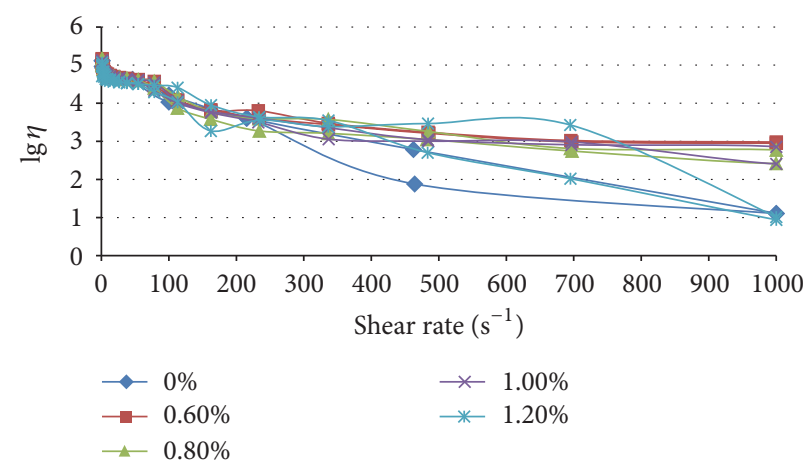

(b)

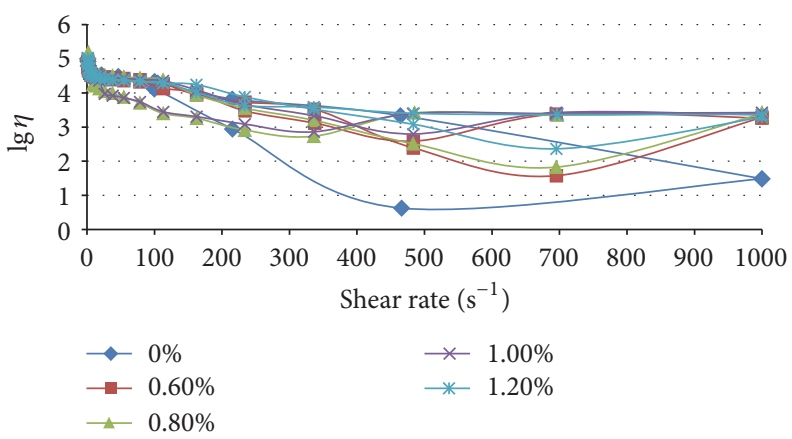

(c)

Figure 9: Curves of thixotropy of samples at temperatures, ${ }^{\circ} \mathrm{C}$ : (a) 80; (b) 85; (c) 90.

TABLE 10: Results of laboratory tests of oxidized bitumen 60/90.

\begin{tabular}{|c|c|c|c|c|c|c|c|}
\hline \multirow[t]{2}{*}{ Number } & \multirow[t]{2}{*}{ Indicators } & \multirow{2}{*}{$\begin{array}{l}\text { GOST 22245-90 } \\
\text { requirements }\end{array}$} & \multirow{2}{*}{ Original } & \multicolumn{3}{|c|}{ Bitumen samples } & Adhezoline content, wt.\% \\
\hline & & & & 0.6 & 0.8 & 1.0 & 1.2 \\
\hline \multirow[t]{3}{*}{ (1) } & Penetration, $0.1 \mathrm{~mm}$ : & Not below & & & & & \\
\hline & at $25^{\circ} \mathrm{C}$ & $61-90$ & 73 & 75 & 81 & 86 & 78 \\
\hline & at $0^{\circ} \mathrm{C}$ & 20 & 25 & 30 & 30 & 25 & 23 \\
\hline$(2)$ & Softening temperature $\left(T_{\text {soft }}\right),{ }^{\circ} \mathrm{C}$ & Not below 47 & 51.4 & 49.8 & 49.6 & 50 & 49 \\
\hline \multirow[t]{3}{*}{ (3) } & Ductility, $\mathrm{cm}$ & Not less than & & & & & \\
\hline & at $25^{\circ} \mathrm{C}$ & 55 & 89 & 128 & 116 & 110 & 120 \\
\hline & at $0^{\circ} \mathrm{C}$ & 3.5 & 4.5 & 4.9 & 5.0 & 4.5 & 4.9 \\
\hline \multirow[t]{5}{*}{$(4)$} & Adhesion to crushed stone, points & & & & & & \\
\hline & (1) Pervouralsk & & 2 & 4 & 4 & 5 & 5 \\
\hline & (2) Sangalyk & & 2 & 4 & 4 & 5 & 5 \\
\hline & (3) Bianca & Is not regulated & 3 & 5 & 5 & 5 & 5 \\
\hline & (4) Valegin Bor & & 2 & 4 & 5 & 5 & 5 \\
\hline$(5)$ & Penetration index & From -1 to +1 & 0.1 & -0.2 & $-0,1$ & 0,2 & $-0,3$ \\
\hline \multirow[t]{2}{*}{ (6) } & \multirow[t]{2}{*}{ Brittleness temperature, ${ }^{\circ} \mathrm{C}$} & $\begin{array}{l}\text { Not higher than minus } \\
15\end{array}$ & Minus & Minus & Minus & Minus & Minus \\
\hline & & 15 & 22.9 & 23.7 & 25.7 & 29.1 & 28.8 \\
\hline
\end{tabular}

coagulation structure in the bitumen [31]. It is likely that this specific concentration in the bitumen is $0.8 \mathrm{wt} . \%$, which we called the "active state" (Section 3.3).

3.5. The Effect of PFM on Bitumen Performance Properties. The results of laboratory tests carried out on bitumen modified using $0.6,0.8,1.0$, and $1.2 \mathrm{wt} . \%$ of additive are presented in Table 10 in comparison with the GOST 2224590 requirements.
The interrelation between the changes in the quality indicators of bitumen given in Table 10 can be explained on the basis of the specificity of the action of the synthesized reagent and its subsequent polymerization activity when the group component composition and the particle size of the dispersed phase change. Thus, according to $T_{\text {soft }}$ value changes, the concentration of PFM of $0.6 \mathrm{wt} . \%$ is characterized by an increase in the structure formation $\left(T_{\text {soft }}=128^{\circ} \mathrm{C}\right)$ and an increase in the mechanical strength of the ODS; with an 
increase in the concentration of PFM up to to $0.8-1.0 \mathrm{wt} . \%$ we observe a sharp drop in the value of softening point, to $116^{\circ} \mathrm{C}$ and $110^{\circ} \mathrm{C}$, respectively. Apparently, this indicates the disaggregation of resinous-asphaltene particles (RAS) in the dispersion medium of the modified bitumen by the PFM.

The indicator "penetration index" (PI) is considered as a reflection of the colloidal structure of bitumen. Taking into account the fact that with the change of penetration of bitumen the ductility indicator passes through the maximum value, the penetration index is limited from -1 to +1 . It is known that the PI indicator accurately characterizes the elastic properties of bitumen and their dependence on temperature $[15,31]$. For the studied samples, the PI indicator changes from +0.1 (for the original unmodified bitumen) to the values of $-0.2 ;-0.1 ;+0.2$ for the concentrations (wt.\%) of PFM equal to $0.6 ; 0.8 ; 1.0$, respectively. Thus, the increase in the content of PFM up to $1.0 \mathrm{wt} . \%$ increases the elasticity of modified bitumen. At the same time, an important trend is observed: the further increase in the concentration of additive up to $1.2 \mathrm{wt}$.\% leads to a sharp decrease in PI to -0.3 , which is directly proportional to the penetration indicator. This indicates the activation of the structure formation of the disperse system of modified bitumen.

The use of bitumen as film-forming base in asphalt materials is justified primarily by the fact that the rate of diffusion of water into the bitumen is $0.83 \cdot 10^{-15}-1.66$. $10^{-15} \mathrm{~kg} \cdot \mathrm{m} /(\mathrm{s} \cdot \mathrm{N})$ [5]; this causes low solubility of water in the bitumen. As mentioned above, the degree of adhesion between the bitumen and the stone material depends on the chemical nature of the components and, therefore, the variety of types of bitumen and the stone material $[4,16]$.

The process of adhesive bond forming is usually divided into two stages. The first is the so-called transport stage, during which adhesive molecules move to the surface of the substrate (body on which the adhesive is applied) and the functional groups of the adhesive interact, orientating in the interphase layer. This results in intimate contact of molecules and/or associates of the adhesive with the substrate. An increase in temperature and pressure, as well as conversion of one of the phases (typically an adhesive) to the liquid state by dissolving or melting, contributes to the flow of the first stage of the adhesion process. To achieve a more intimate contact between the adhesive and the substrate we can apply more thorough cleaning of the interacting surfaces. The adhesion second step consists in direct intermolecular interaction of the adhesive and substrate, which may be caused by the different forces, from van der Waals to chemical forces. Intermolecular interactions of contacting phases complete the adhesion process, and that corresponds to the minimum of interfacial (surface) energy [16].

We have developed a polyfunctional modifier of complex action that is a nonclassical cationic surfactant, as mentioned above. Based on the foregoing conceptualization, it is possible to assume that the efficiency of PFM is due to the presence of discontinuities in hydrophobic hydrocarbon chains caused by presence of polar heteroatomic moieties which provide the required hydrophilic-lipophilic balance (HLB) as well as

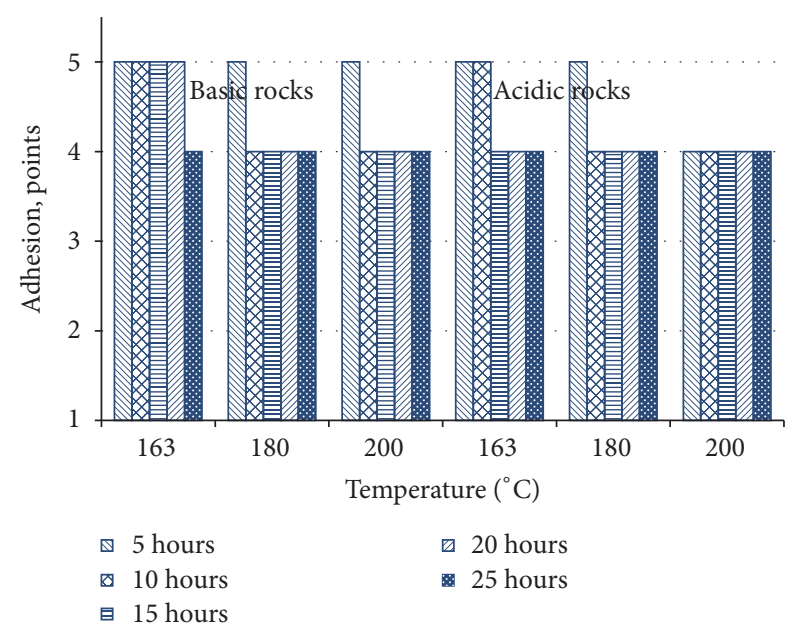

FIgURE 10: Thermal stability of bitumen modified with the use of PFM.

the optimal location of these polar groups and hydrophobic hydrocarbon radicals in the adhesive molecule. In addition, in this case the length of the nonpolar hydrocarbon chains and their location has a great influence. All this allows us to provide the most effective interaction of PFM with the surface of the dispersed phase and the volume of the dispersion medium.

According to the existing technology of preparation of asphalt mixtures used in the asphalt plants, asphalt undergoes high temperatures. The essential drawback of adhesive additives currently used in road construction is their thermal instability (up to $140-150^{\circ} \mathrm{C}$ ).

The results of research for the thermal stability of bitumen modified by PFM (as determined above, the optimal amount of 0.8 wt.\% was doped) are presented in Figure 10.

As can be seen from the data presented in Figure 10, the temperature control at $163^{\circ} \mathrm{C}$ for 20 hours provides the adhesion degree evaluated with 5 points, which corresponds to the control sample No. (1). Increasing the heating duration at the same temperature for up to 25 hours leads to some reduction in adhesion. An influence of temperature of $180^{\circ} \mathrm{C}$ and $200^{\circ} \mathrm{C}$ for 10 hours and more leads to a decrease in adhesion down to 4 points. It should be noted that the bitumen without additive has shown insufficient adhesion both with basic and acidic rocks, namely, 3 points after thermal exposure for 5 and 10 hours and 2 points after 15-25 hours thermal exposure (at all the temperatures).

Thus, the synthesized polyfunctional modifier significantly improves the adhesion of the bitumen to the surface of the mineral material and pavements with enhanced thermal stability.

We had conducted pilot-scale tests with the road constructing organization ZAO Trest Kamdorstroy. The results of technical inspection have shown that asphalt concrete mixtures obtained with the use of modified bitumen meet the GOST 22245-90 specification quality requirements. 
Field tests carried out to assess the physical and mechanical characteristics of asphalt concrete mixtures based on bitumen BND 60/90 produced by JSC “TAIF-NK," modified using 1 wt.\% of PFM, taken from the coating after two years and 9 months of operation of the roadway, have shown that these asphalt mixes fully comply with GOST 91282009 "Mixtures of asphalt concrete road, airfield and asphalt concrete."

Thus, the results obtained give grounds to judge the increase in the between-repair time of the road surface, and, as a consequence, its durability as a result of the use of PFMmodified bitumen.

\section{Conclusion}

The experimental data indicate a high capacity of $\mathrm{N}$-acylated derivatives of bisimidazolines to improve the adhesion of bitumen to mineral materials, as well as the plasticity of bitumen, while providing increased (up to $220-240^{\circ} \mathrm{C}$ ) thermal stability. The polyfunctional modifier can be used as complex additives for bitumen used in road and civil construction, regardless of the nature of used aggregates (basic or acidic) and regardless of the change in composition of the original bitumen.

Thus, it was found that the presence of an adhesive additive in the bitumen significantly changes the wetting of the mineral substrate with modified bitumen. The wetting inversion is observed; $\cos \theta$ increases with increasing content of the additive; it acquires positive values; the work of adhesion increases, reaching a peak with an additive content of $0.8 \%$ by weight; the work of cohesion and the surface tension between the liquid and solid phases decrease.

It has been established that the smallest particle diameter corresponds to the dosage of the additive in the bitumen of $0.8 \%$ by weight, so that it can be concluded that the additive has a structuring effect on the properties of road bitumen.

The use of PFM leads to improved performance properties enabled by lowering the binder sensitivity to temperature changes and load time susceptibility as well as providing high adhesion between the binder and aggregates at elevated temperatures in combination with high elasticity at low temperatures.

Finally, it should be noted that, from January 2015 to January 2016, the experiments were conducted to evaluate the adhesive properties of bitumen in various weather conditions. So, on January 14, 2015, a previously prepared sample of bitumen modified by PFM in the amount of $1 \mathrm{wt}$. $\%$ was placed outside and kept under different weather conditions for one year, after which the sample of the bitumen was monthly examined for its adhesion properties. Over a year, outside temperatures changed from minus $25^{\circ} \mathrm{C}$ in winter to plus $35^{\circ} \mathrm{C}$ in the summer. The obtained data on the evaluation of adhesion proved to be quite satisfactory. Bitumen has not lost its adhesive properties during the whole period of storage in the open air at various temperatures, which can also indirectly confirm the increased durability of this kind of bitumen and asphalt concrete on its basis.

\section{Conflicts of Interest}

The authors declare that they have no conflicts of interest.

\section{Acknowledgments}

The work is performed according to the Russian Government Program of Competitive Growth of Kazan Federal University. This work was funded by the subsidy allocated to Kazan Federal University for the state assignment in the sphere of scientific activities (10.7636.2017/7.8).

\section{References}

[1] R. Hunter, The Shell Bitumen Handbook, ICE Publishing, London, UK, 6th edition, 2014.

[2] L. M. Gokhman, "Bitumens, bitumen-polymer binders, asphalt concrete, polymeric asphalt concrete, study guide" (Russian), p. 117, ZAO “ECON-INFORM”, 2008.

[3] S. Manolis, "Engineering properties of asphalt cement binders and their relation to pavement performance," Royal Military College of Canada, Coco Paving Inc., 2014, http://www.asphaltinstitute.org/wp-content/uploads/Thickness_Mix/2014-pptbyManolisEngineeringPropertiesofACBindersandRelationtoPavementPerformance.pdf.

[4] A. F. Burger, M. F. C. van de Ven, J. Muller, and K. J. Jenkins, "Rheology of polymer modified bitumen: A comparative study of three binders and three Binder/filler systems," in Proceedings of the 20th South African Transportation Conference "Meeting the Transport Challenges in Southern Africa", 2001.

[5] A. F. Kemalov and R. A. Kemalov, "Study of disperse polymer systems for producing high-quality polymeric-bituminous materials," Chemistry and Technology of Fuels and Oils, vol. 48, no. 5, pp. 339-343, 2012.

[6] X. Lu, Y. Talon, and P. Redelius, "Aging of bituminous binders - laboratory tests and field data," in Proceedings of the E\&E Congress, Copenhagen, Denmark, 2008.

[7] S. Cui, B. R. K. Blackman, A. J. Kinloch, and A. C. Taylor, "Durability of asphalt mixtures: Effect of aggregate type and adhesion promoters," International Journal of Adhesion and Adhesives, vol. 54, pp. 100-111, 2014.

[8] A. Chomicz-Kowalska, W. Gardziejczyk, and M. M. Iwański, "Moisture resistance and compactibility of asphalt concrete produced in half-warm mix asphalt technology with foamed bitumen," Construction and Building Materials, vol.126, pp. 108118, 2016.

[9] A. A. Abramzon, V. V. Bocharov, G. M. Gayevoy et al., Surfactants, Khimiya, Leningrad, Russia, 1979, (Russian).

[10] D. N. Rubingh and P. M. Holland, Cationic Surfactants: Physical Chemistry, vol. 37 of Surfactant Science, Marcel Dekker Inc., New York, NY, USA, 1990.

[11] J.-Z. Ai, X.-P. Guo, J.-E. Qu, and Z.-Y. Chen, "Adsorption behavior of imidazoline amide on the surface of galvanic electrode," Acta Physico - Chimica Sinica, vol. 21, no. 10, pp. 1096-1101, 2005.

[12] V. V. Krut', A. B. Solomentsev, V. P. Kolodezny et al., "Adhezion additive of polyfunctional action," pat. 2130954 Russian Federation: IPC C08L95/00, C08K5/3415/ applicant and patent holder OAO Oreldorstroy - No. 97100884/04. 
[13] A. F. Kemalov, R. A. Kemalov, and I. M. Abdrafikova, "The use of plant oils for gaining the colored plastoconcrete," Biosciences Biotechnology Research Asia, vol. 11, no. 3, pp. 1699-1706, 2014.

[14] S. Kishchynskyi, V. Nagaychuk, and A. Bezuglyi, "Improving Quality and Durability of Bitumen and Asphalt Concrete by Modification Using Recycled Polyethylene Based Polymer Composition," Procedia Engineering, vol. 143, pp. 119-127, 2016.

[15] I. I. Mukhamatdinov, Bitumen binders modified with the use of cationic-active adhesion additive [Ph.D. Thesis], Kazan Federal University, 2015.

[16] NPCS Board of Consultants \& Engineers, The Complete Technology Book on Industrial Adhesives, Asia Pacific Business Press Inc., Delhi, India, 2008.

[17] P. S. Fakhretdinov, "The concept of non-classic cationic surfactants," in Proceedings of the XVIII Mendeleev Congress on General and Applied Chemistry, vol. 1, p. 483, Moscow, Russia, 2007.

[18] P. S. Fakhretdinov and G. V. Romanov, "The concept of nonclassic surfactants is the basis for the creation of new highly effective reagents for the petroleum industry," in Proceedings of the the 2nd Russian Scientific-Practical Conference "Practical Aspects of oilfield chemicals", p. 104, Ufa, Russia, 2012.

[19] A. F. Kemalov and R. A. Kemalov, "Practical Aspects of Development of Universal Emulsifiers for Aqueous Bituminous Emulsions," World Applied Sciences Journal, vol. 23, no. 6, pp. 858-862, 2013.

[20] A. P. Kreshkov, L. N. Bykova, and N. A. Kazaryan, Acid-Base Titrations in Non-Aqueous Solutions, Khimya, Moscow, Russia, 1967.

[21] B. N. Tarasevich, IR Spectra of the Main Classes of Organic Compounds. Reference Materials, M.V. Lomonosov Moscow State University, Moscow, Russia, 2012.

[22] GOST 12801-98, "Materials based on organic binders for road and airfield construction. Test methods," 1999.

[23] A. W. Neumann and R. J. Good, "Techniques of measuring contact angles," in Surface and Colloid Science, R. J. Good and R. R. Stromberg, Eds., vol. 11, pp. 31-91, Springer, New York, NY, USA, 1979.

[24] GOST 22245-90, "Viscous petroleum road bitumens. Specifications," 1991.

[25] GOST 18180-72, "Petroleum bitumens. Method for determination of mass change after heating," 1973.

[26] GOST 3900-85, "Petroleum and petroleum products. Methods for determination of density," 1987.

[27] GOST 33-2000, "Petroleum products. Transparent and opaque liquids. Determination of kinematic viscosity and calculation of dynamic viscosity," 2002.

[28] ASTM D 2872, "Standard test method for effect of heat and air on moving film of asphalt (Rolling thin-film oven test)," Tech. Rep.

[29] GOST 9128-2009, "Asphalt concrete mixtures for roads and airdromes, and asphalt concrete. Technical specifications," 2011.

[30] R. B. Gun, Petroleum Bitumen, Chemistry, Moscow, Russia, 1973.

[31] S. M. Petrov, Modifiers of multifunctional action for obtaining oxidized road bitumen with improved properties [Ph.D. Thesis], Kazan State Technological University, Kazan, Russia, 2009.

[32] B. P. Tumanyan, Scientific and Applied Aspects of the Theory of Oil Dispersed Systems, Tekhnika, Moscow, Russian, 2000.

[33] G. I. Fuchs, Viscosity and Plasticity of Petroleum Products, Institute for Computer Research, Moscow-Izhevsk, 2003. 


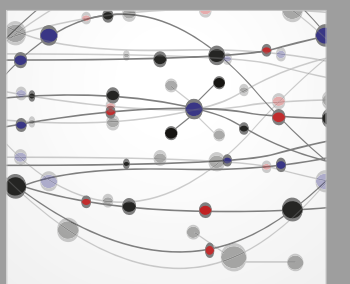

The Scientific World Journal
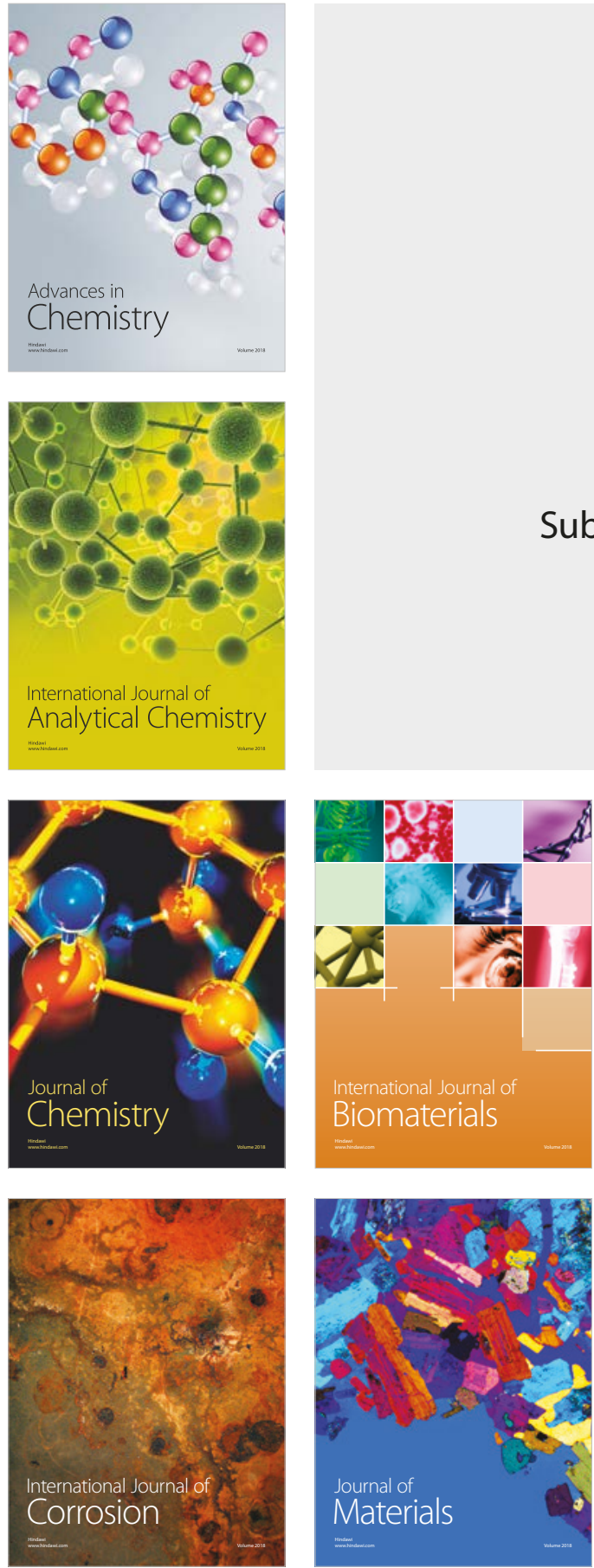

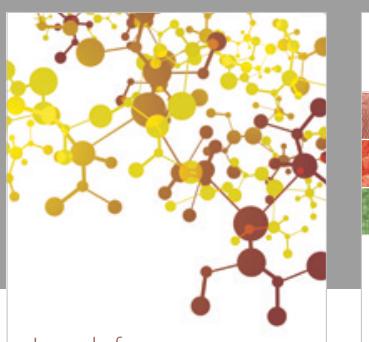

Journal of

Applied Chemistry
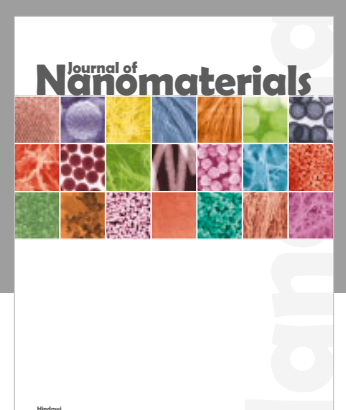

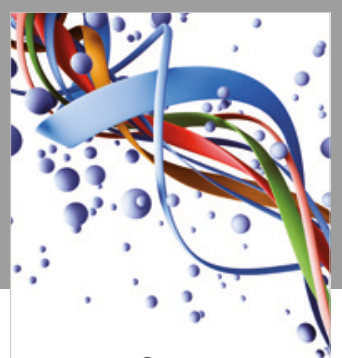

Scientifica

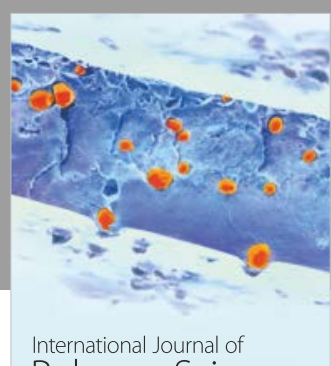

Polymer Science

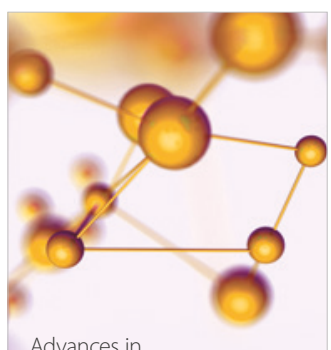

Physical Chemistry
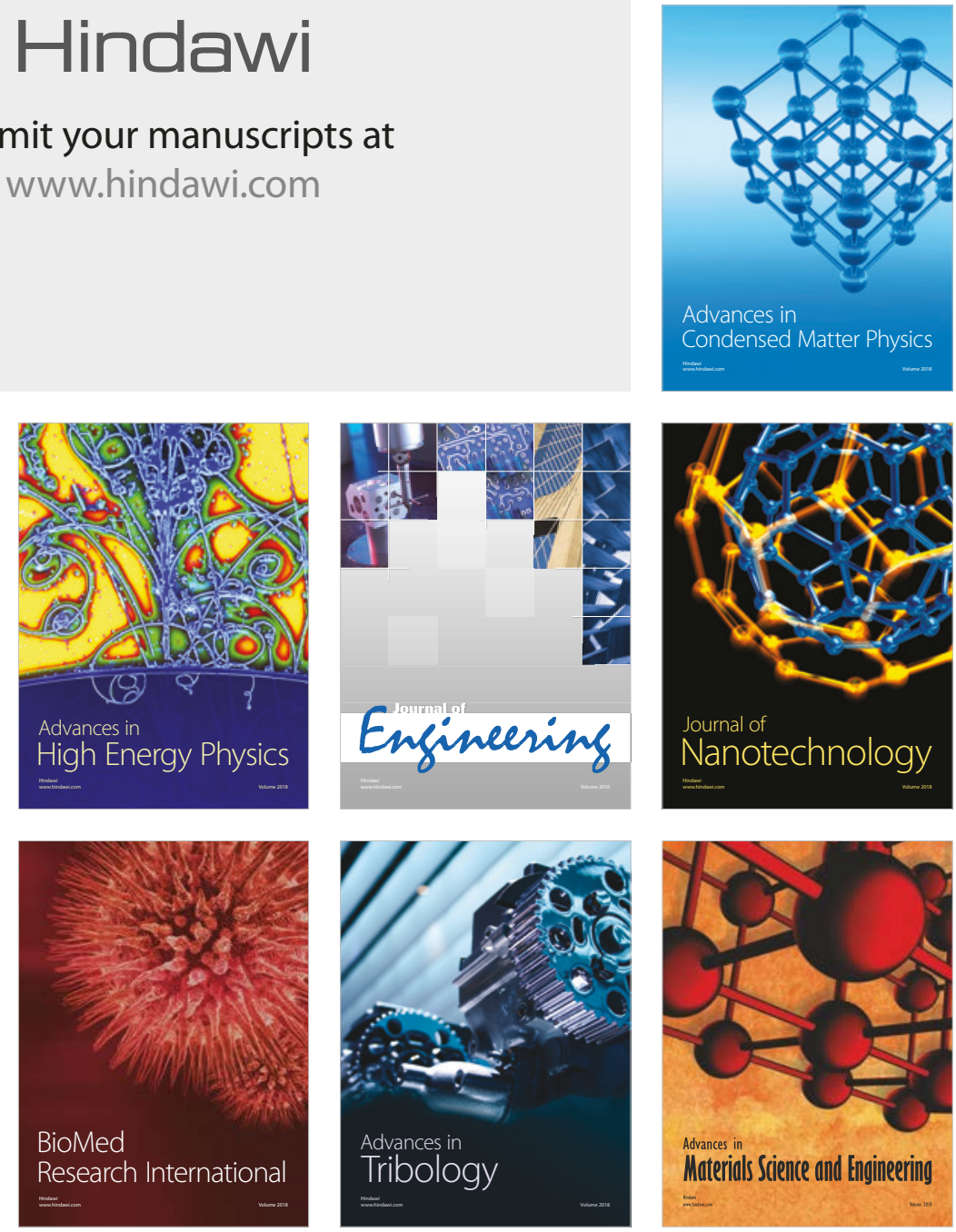